\title{
EFFECT OF REYNOLDS NUMBER ON THE SUCTION INFLUENCE ON THE TURBULENT BOUNDARY LAYER STRUCTURES
}

\author{
M. O. Oyewola \\ University of Newcastle \\ Discipline of Mechanical Engineering \\ School of Engineering \\ NSW, 2308, Australia \\ meoo@alinga.newcastle.edu.au \& \\ ooyewola@yahoo.com
}

\begin{abstract}
The effect of Reynolds number on the influence of suction on the turbulent boundary layer structures has been quantified through the measurements of third- and fourth-order turbulence statistics for several suction rates and streamwise locations downstream of the suction strip. Third- and fourthorder turbulence statistics are more sensitive to a change in boundary condition than second-order moments. The data of the third-order turbulent statistics reveal an alteration in the turbulent transport as a result of the manipulation of the organised motion by suction. The alteration is increased as the suction rate is increased but reduces as the Reynolds number is increased. The results support that, relative to no suction case, Reynolds number modulates the behaviour of higher-order turbulent statistics without changing the actual mechanism of suction on the boundary layer. In general, it is proposed that Reynolds number effect on suction influence in a turbulent boundary layer is universal for the large-scale quantities. This argument is supported by the behaviour of root mean square fluctuating spanwise vorticity.
\end{abstract}

Keywords: boundary layer, suction, structures, measurements

\section{NOMENCLATURE}

$\mathrm{A}_{\mathrm{w}} \quad$ cross-sectional area

b width of the strip, $m$

D pipe diameter, $\mathrm{m}$

$\mathrm{h}$ height of the groove, $\mathrm{m}$

$\mathrm{L}$ pipe length, $\mathrm{m}$

$\mathrm{p}$ pressure, $\mathrm{N} / \mathrm{m}^{2}$

q turbulent energy, $\mathrm{Nm}$

$\mathrm{Q}_{\mathrm{r}} \quad$ flow rate, $\mathrm{m}^{3} / \mathrm{s}$

$\mathrm{R}_{\theta 0} \quad$ Reynolds number based on momentum thickness without suction, $\mathrm{U}_{1} \theta_{\mathrm{o}} / v$

$\mathrm{R}_{\theta} \quad$ momentum thickness Reynolds number, $\mathrm{U}_{1} \theta / v$

$\mathrm{u}, \mathrm{v}, \mathrm{w}$ velocity components, $\mathrm{m} / \mathrm{s}$

$\mathrm{U}$ mean velocity, $\mathrm{m} / \mathrm{s}$

$\mathrm{U}_{1} \quad$ free stream velocity, $\mathrm{m} / \mathrm{s}$

$\mathrm{U}_{\infty} \quad$ free stream velocity, $\mathrm{m} / \mathrm{s}$

$\mathrm{U}_{\tau} \quad$ friction velocity, $\mathrm{m} / \mathrm{s}$

$\mathrm{V}_{\mathrm{w}} \quad$ suction velocity, $\mathrm{m} / \mathrm{s}$

$\mathrm{x}, \mathrm{y}, \mathrm{z}$ cartesian coordinates, $\mathrm{m}$

\section{Greek symbols}

$\sigma \quad$ normalized suction rate (severity index)

$\delta \quad$ boundary layer thickness, $m$

$\theta \quad$ momentum thickness, $\mathrm{m}$

$\theta_{0} \quad$ momentum thickness without suction, $\mathrm{m}$

$v$ fluid kinematic viscosity, $\mathrm{m}^{2} / \mathrm{s}$

$\omega \quad$ vorticity

$\rho \quad$ density, $\mathrm{kg} / \mathrm{m}^{3}$

$\tau_{\mathrm{w}} \quad$ wall shear stress, $\mathrm{N} / \mathrm{m}^{2}$

\section{Subscripts / Superscripts}

o without suction

w wall

$\propto \quad$ free stream

1 free stream

, root mean square (r.m.s.)

\section{INTRODUCTION}

The concept of perturbing a turbulent boundary layer has been a subject of interest for researchers both from experimental and theoretical point of views (Sano and Hirayama, 1985; Antonia et al., 1988; Antonia et al., 1995, Park and Choi, 1999; Krogstad and Kourakine, 2000; Oyewola et al., 2003). This was likely motivated from the fact that the near-wall coherent structures play a significant role in the transport of turbulent (Cantwell, 1981; Robinson, 1991). Also, the great increase in the numbers of literatures about the descriptions, formation, size, strength, shape and dynamics of these structures (Kline et al., 1967; Johansson and Alfredsson, 1982; Jeong and Hussain, 1995; Jeong et al. 1997; Chacin and Cantwell, 2000) have increased our understanding in the perceptive of interfering with these structures. For example, Kline et al., 1967 explained the near-wall boundary structure with a hairpin vortex through their flow visualization of the wall streaks. They found that a dynamically unstable shear layer is produced, rotated and stretched in the 
downstream direction when a spanwise vortex tube is lifted up. Similarly, Jeong et al., 1997 results indicated that near-wall turbulence structure generally have a finite inclination to the wall, and interact in a cooperative manner to perpetuate turbulence. Therefore, through appropriate means, it is possible to suppress, weaken, alter or even eradicate these structures, and thereby, enhance the control of the boundary layer.

In that respect, suction has been used in various ways in interfering with the near-wall structures and quite a number of interesting results has emanated from it (Sano and Hirayama, 1985; Antonia et al., 1988; Antonia et al., 1995; Oyewola et al., 2001, 2003). Such results include the reduction in the intensity of the velocity and Reynolds shear stress, increase or decrease in skin friction based on the suction rate. Also, an interesting result feature, which emerged from the flow visualizations result of Antonia et al., 1988, was the increased stability of the near-wall flow by suction, as reflected by a more orderly behaviour of the low-speed and high-speed streaks and a greater longitudinal coherence of the low-speed streaks as compared with their no suction counterpart. Since increase in Reynolds number always accompany with a change in the near-wall structure. It is necessary to investigate how this increase in Reynolds number influence the effect suction has on the near-wall structure. Oyewola et al. (2001, 2003) studied the combined influence of the Reynolds number and localised wall suction, applied through a short porous wall strip on a turbulent boundary layer. Through the measurements of skin friction, mean velocity and Reynolds stresses, they found that both the suction rate, $\sigma$, and the momentum thickness Reynolds number, $\mathrm{R}_{\theta}$ played important role in the relaminarisation process. For instance, they found that pseudo-relaminarisation occurred for $\mathrm{R}_{\theta \mathrm{o}}=660$ and $\sigma=3.3$; the streamwise extents of it is increased as $\sigma$ is increased, but when $\mathrm{R}_{\theta \mathrm{o}}=1400$, no pseudo-relaminarisation was observed for all $\sigma$ 's. Oyewola (2004) obtained a similar result through the measurements of correlation coefficient and structural parameter. It should be emphasized that mean velocity and second-order statistics are not as sensitive to a change in boundary condition as compare with higher-order statistics.

In this present work, which extends the work of Oyewola et al. $(2001,2003)$ and Oyewola (2004), is to quantify further the effect of Reynolds number on the suction influence on the turbulent boundary layer structures. This effect is quantifying through the measurements of third and fourth-order turbulent statistic at various Reynolds number and suction rates and for a series of streamwise locations downstream of the suction strip. Also, measurement of the spanwise vorticity is quantifying.

\section{EXPERIMENTAL DETAILS}

Experiments were carried out in a zero-pressure gradient two-dimensional turbulent boundary layer, which is subjected to concentrated suction, applied through a short porous strip. The turbulent boundary layer develops on the floor of the rectangular working section (Figure 1) after it is tripped at the exit from the contraction using a $100 \mathrm{~mm}$ roughness strip. Tests showed that the boundary layer was fully developed at the suction strip location, which is about $1200 \mathrm{~mm}$ downstream of the roughness strip. Measurements were made at $U_{\infty}$ of 3.25 and $7 \mathrm{~ms}^{-1}$; the corresponding values of the initial momentum thickness Reynolds numbers $\mathrm{R}_{\theta \mathrm{o}}$ are 660 and 1400 , respectively. A $3.25 \mathrm{~mm}$ thick porous strip with a width of $40 \mathrm{~mm}$ and made of sintered bronze with pore sizes in the range $40-80 \mu \mathrm{m}$ or $(0.4-0.9) \nu / \mathrm{U}_{\tau}$ was mounted flush with the test section floor. Allowing for the width of the mounting recess step, the effective width $(=b)$ of the strip was $35 \mathrm{~mm}$. Suction was applied through a plenum chamber located underneath the suction strip and connected to a suction blower, driven by a controllable DC motor, through a circular pipe (internal diameter $\mathrm{D}=130$ $\mathrm{mm}$ and $\mathrm{L} / \mathrm{D} \approx 38$, where, $\mathrm{L}$, is the pipe length). The flow rate $\mathrm{Q}_{\mathrm{r}}$ was estimated directly by radially traversing a Pitot tube located near the end of the pipe, for various values of the pipe centre-line velocity $\left(U_{c}\right)$. A plot of $Q_{r}$ vs $U_{c}$, allowed the suction velocity $\left(\mathrm{V}_{\mathrm{w}}\right)$ to be inferred via the continuity equation $\left(\mathrm{Q}_{\mathrm{r}}=\mathrm{A}_{\mathrm{w}} \mathrm{V}_{\mathrm{w}}\right.$, where, $\mathrm{A}_{\mathrm{w}}$ is the crosssectional area of the porous strip). The suction velocity was assumed to be uniform over the porous surface; this assumption seems reasonable if the variation in the permeability coefficient of the porous material is $\pm 3 \%$.
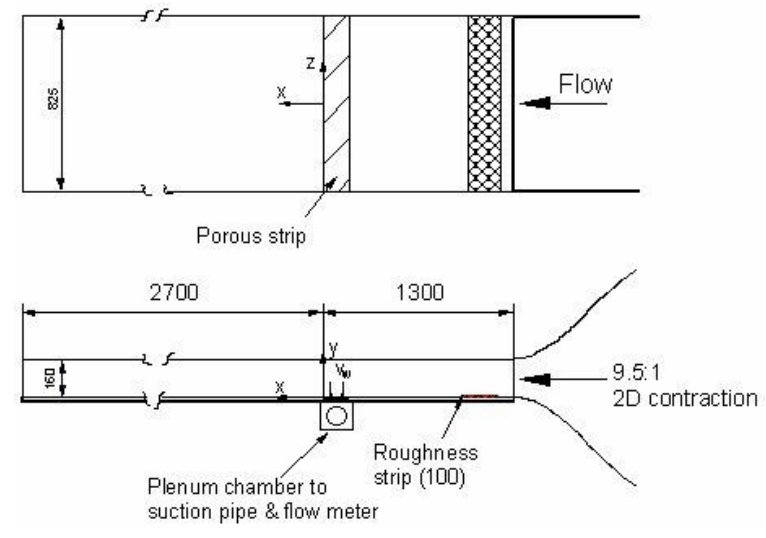

Figure 1. Schematic arrangement of the working section

Measurements were made for $\sigma$ (normalised suction rate, severity index as introduced by Antonia et al., $\left.1995=\mathrm{V}_{\mathrm{w}} \mathrm{b} / \theta_{\mathrm{o}} \mathrm{U}_{\infty}\right)=0,1.7,3.3$ and 5.5. The results at $\sigma=0$ provided a reference against which 
the suction data could be appraised. The wall shear stress $\tau_{\mathrm{w}}$ was measured with a Preston tube $(0.72 \mathrm{~mm}$ outer diameter), and a static tube located approximately $35 \mathrm{~mm}$ above it at the same x position. The Preston tube was calibrated in a fully developed channel flow using a similar method to that described in Shah and Antonia, 1989 and Antonia et al., 1995. $\tau_{\mathrm{w}}$ was determined from the relation $\tau_{\mathrm{w}}=-\mathrm{h}(\mathrm{dp} / \mathrm{dx})$, where $h$ is the channel half-width and $p$ is the static pressure. Measurements of the velocity fluctuations in the streamwise and wall normal directions were made with cross wires, each inclined at $45^{\circ}$ to the flow direction. The etched portion of each wire (Wollaston, Pt-10\% Rh) had a diameter of $2.5 \mu \mathrm{m}$, and a length to diameter ratio of about 200. The separation between the inclined wires was about 0.6 $\mathrm{mm}$. Vorticity measurements were made with a probe comprising a cross-wire and two parallel hot-wires. The parallel single wires were orthogonal to the plane of the X-probe and located on either side of the centre of the X-probe (see Antonia and Rajagopalan (1990) for more details). The single wires were separated by a distance $\Delta \mathrm{y}=1.1 \mathrm{~mm}$ ( $\mathrm{y}$ is the normal direction to the wall), while the distance between the X-wires was about $1.23 \mathrm{~mm}$. All hot wires were operated with inhouse constant temperature anemometers at an overheat ratio of 1.5. The analog output signal of the hot wire was low pass filtered at $5 \mathrm{kHz}-8 \mathrm{kHz}$, offset and amplified to within $\pm 5 \mathrm{~V}$. The performance of the vorticity probe was checked by comparing the velocity fluctuations with those measured using a single $\mathrm{X}$-wire for the same flow conditions. The results (not shown here) showed reasonable agreement between the velocity fluctuations of the two measuring techniques. The uncertainty is less than $2 \%$.

\section{RESULTS AND DISCUSSION}

The distributions of third- and fourth-order turbulent statistics at $\mathrm{x} / \delta_{\mathrm{o}}=3$ for $\mathrm{R}_{\theta \mathrm{o}}=660$ and 1400 are shown in Figure 2. The data when $\sigma=0$ is shown in all the distribution to provide reference for the assessment of the suction data. In all the cases, there is a considerable change in the distributions relative to their no suction counter part. While the distributions of the third-order turbulent statistics reflects a change in the turbulent energy transport, the distributions of the fourth-order reflects a change in the near-wall organise motions. For example, the attenuation of $\left\langle\mathrm{u}^{+2} \mathrm{v}^{+}\right\rangle$and $\left\langle\mathrm{v}^{+3}\right\rangle$ by sution may indicate an alteration in the transport of $\mathrm{u}^{\prime 2}$ and $\mathrm{v}^{\prime 2}$ respectively, by $\mathrm{v}^{\prime}$ velocity fluctuation. In other words, the attenuation in the near-wall region may suggest that the intensity of the wall-normal transport of the sub-layer fluid has been interfered with, give rise to a layer of reduced intensity. This is not surprising, since the turbulence kinetic energy diffusion flux

$$
1 / 2<\mathrm{q}^{2} \mathrm{v}>=1 / 2\left(<\mathrm{u}^{2} \mathrm{v}>+<\mathrm{v}^{3}>+<\mathrm{w}^{2} \mathrm{v}>\right),
$$

the changes in $\left\langle\mathrm{u}^{+2} \mathrm{v}^{+}\right\rangle$and $\left\langle\mathrm{v}^{+3}\right\rangle$ distributions relative to no suction case reflects a suppression in the turbulence kinetic energy diffusion flux due to the eradication of the near-wall coherent structures.

While the reduction observe in $-\left\langle v^{+2} u^{+}\right\rangle$may suggest an alteration in the momentum transport of $\langle u v\rangle$ by $v^{\prime}$ velocity fluctuation, the reduction observed in $<\mathrm{u}^{+3}>$ may suggest a damping of $\mathrm{u}^{\prime 2}$ by $\mathrm{u}^{\prime}$ velocity fluctuation.

It is interesting to observe the same level of attenuations for $\sigma=3.3$ and 5.5 at the inner region of the boundary layer, when suction is applied. The result suggests that no further reduction is possible if $\sigma$ exceed a certain suction rate. This is consistent with the observations that relaminarisation can be achieved downstream of the suction strip for an appropriate combination of the suction rate and Reynolds number Oyewola et al. (2003). The significant changes observe in all the distribution at the outer region $(\mathrm{y} / \delta \geq 0.5)$ reflects a change in the Reynolds number of the boundary layer. This is consistent with the decreased in $R_{\theta}$ observed by Oyewola et al. (2003) when suction was applied.
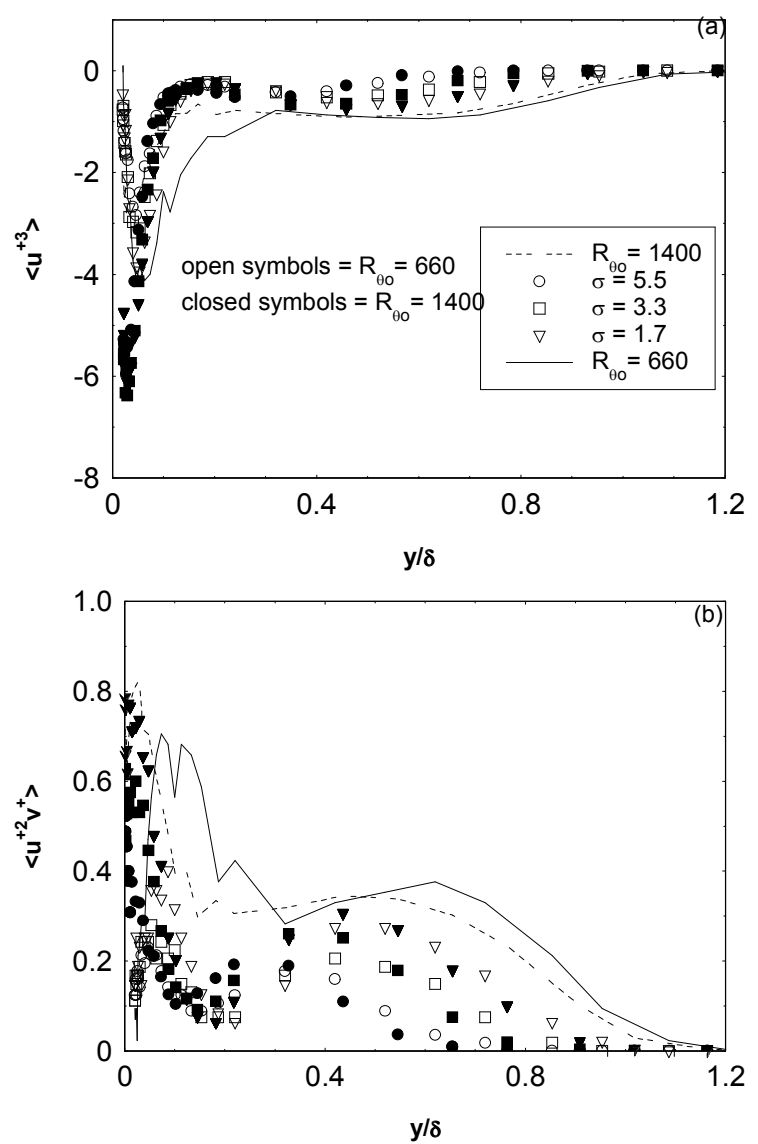

$y / \delta$ 

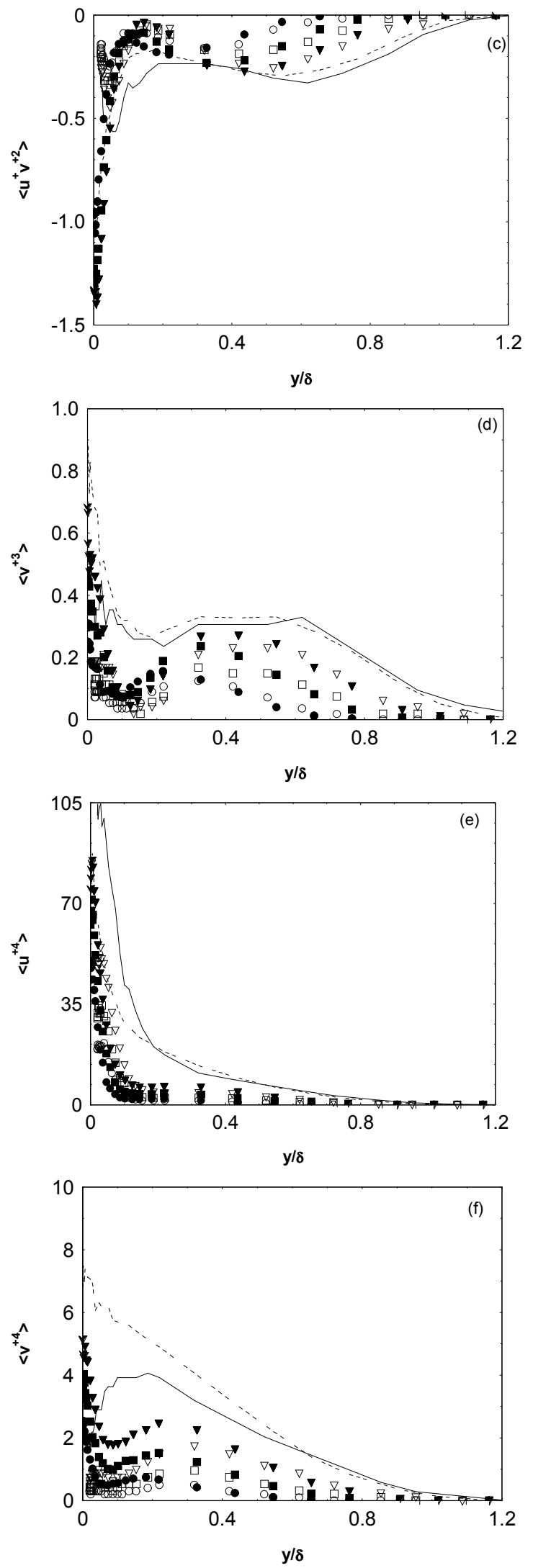

Figure 2. Distribution of normalised third- and fourth-order statistics at $\mathrm{x} / \delta=3$ for several suction rates. Open symbols $=R_{\theta 0}=660$ and closed symbols $=\mathrm{R}_{\theta \mathrm{o}}=1400(\mathrm{a})<\mathrm{u}^{+3}>$; (b) $<\mathrm{u}^{+2} \mathrm{v}^{+}>$; (c) $<\mathrm{u}^{+} \mathrm{v}^{+2}>$; (d) $<\mathrm{v}^{+3}>$; (e) $<\mathrm{u}^{+4}>$; (f) $<\mathrm{v}^{+4}>$.
In Fig. 2e and 2f, the distributions of the fourthorder turbulent statistics show a significant variation both in the inner and outer regions when suction is applied. The attenuation is due to the weakening of the near-wall quasi-coherent structures by suction. This weakening would result in the changes in the near-wall bursting phenomenon. Interestingly, $\left\langle\mathrm{v}^{+4}>\right.$ decease more than $<\mathrm{u}^{+4}>$. This is not surprising since $\left\langle\mathrm{v}^{+2}\right\rangle$ decreased more than $\left\langle\mathrm{u}^{+2}\right\rangle$ (Oyewola et al., 2003), and they are associated with active and inactive motions (Bradshaw, 1967), the results suggest that the active motion is likely to be affected mostly than the inactive motion. The overall result suggest that suction manipulate the organise motions of the boundary layer due to the weakening of the near-wall quasi-coherent structures.

Although, the recovery of the third-order statistics to their corresponding no suction counterparts proceed at different rates, the stages are similar. For example, as the flow advances downstream (Figures 3 and 4), the suction data overshoot, then follows by relaxation to their no suction case. The recovery is strongly been modulated by suction rate for a particular Reynolds number. For example, the overshoot increases with suction rate and the least $\sigma(1.7)$ is the first to recover to their no suction case. The overshoot may suggest a non-linear characteristics of the perturbed boundary layer. Interestingly, when $\mathrm{R}_{\theta_{\mathrm{o}}}=660$ and $\sigma=5.5$, there is no significant overshoot for $\left\langle\mathrm{u}^{+2} \mathrm{v}^{+}\right\rangle$and $\left\langle\mathrm{v}^{+3}\right\rangle$ for all streamwise locations considered. This suggest an indication that possibly relaminarisation of the boundary layer is complete at these Reynolds number and suction rate. This argument is supported by the significant reduction observed for $\left\langle\mathrm{v}^{+4}\right\rangle$ in all the locations.

Similarly, the recovery of the fourth-order statistics follows a similar trend as those of thirdorder statistics. $<\mathrm{u}^{+4}>$ is the first to recover to their no suction counterpart.

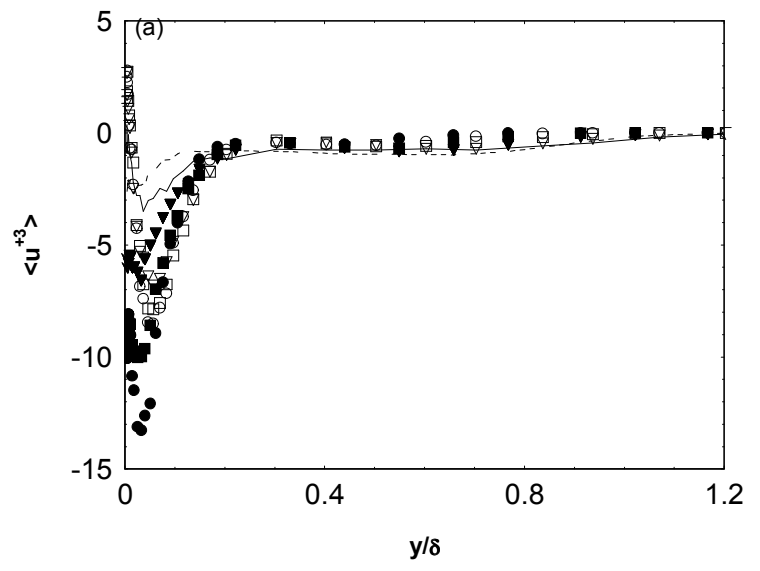



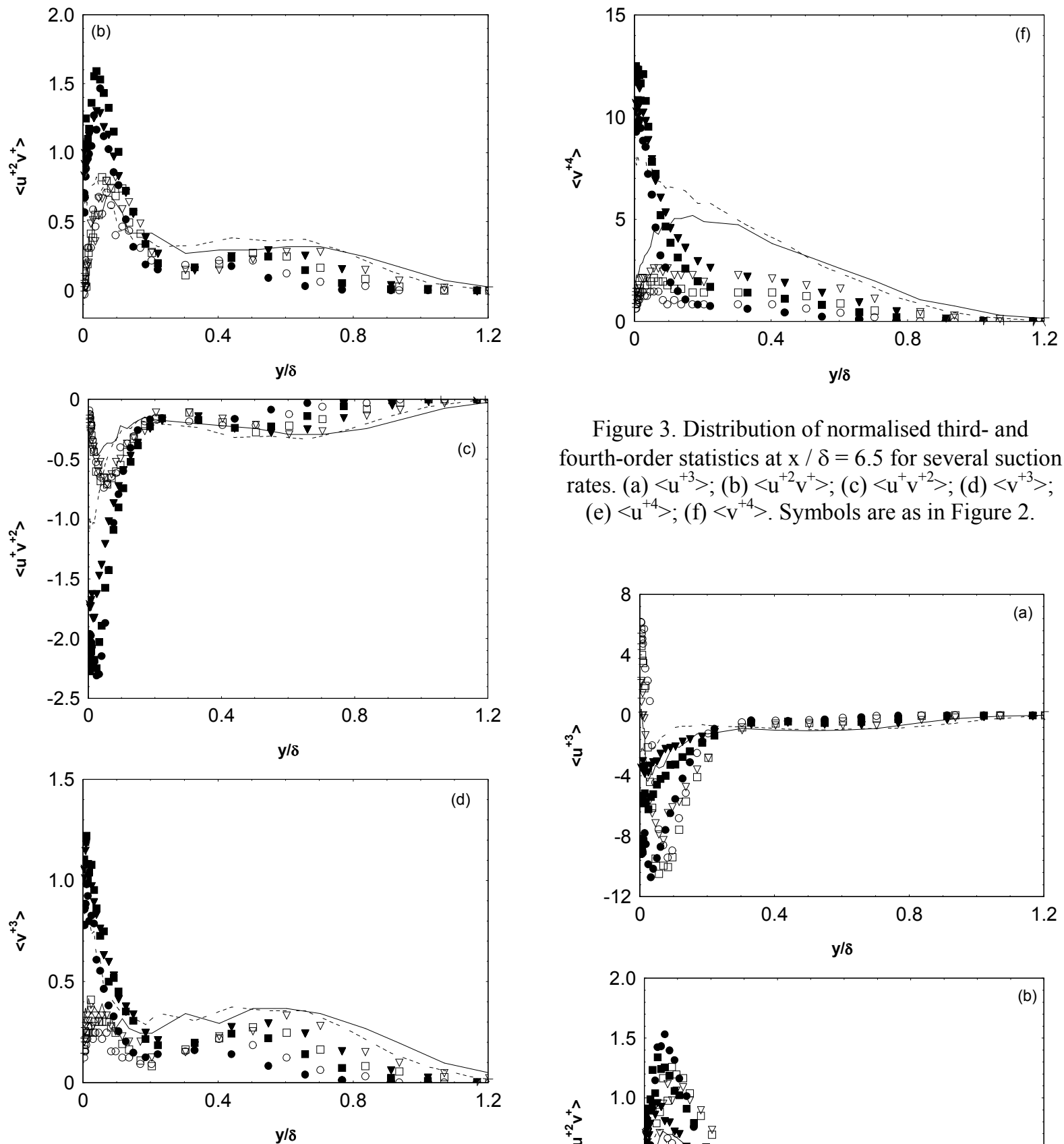

Figure 3. Distribution of normalised third- and fourth-order statistics at $\mathrm{x} / \delta=6.5$ for several suction rates. (a) $<\mathrm{u}^{+3}>$; (b) $<\mathrm{u}^{+2} \mathrm{v}^{+}>$; (c) $<\mathrm{u}^{+} \mathrm{v}^{+2}>$; (d) $<\mathrm{v}^{+3}>$;

(e) $<\mathrm{u}^{+4}>$; (f) $<\mathrm{v}^{+4}>$. Symbols are as in Figure 2.
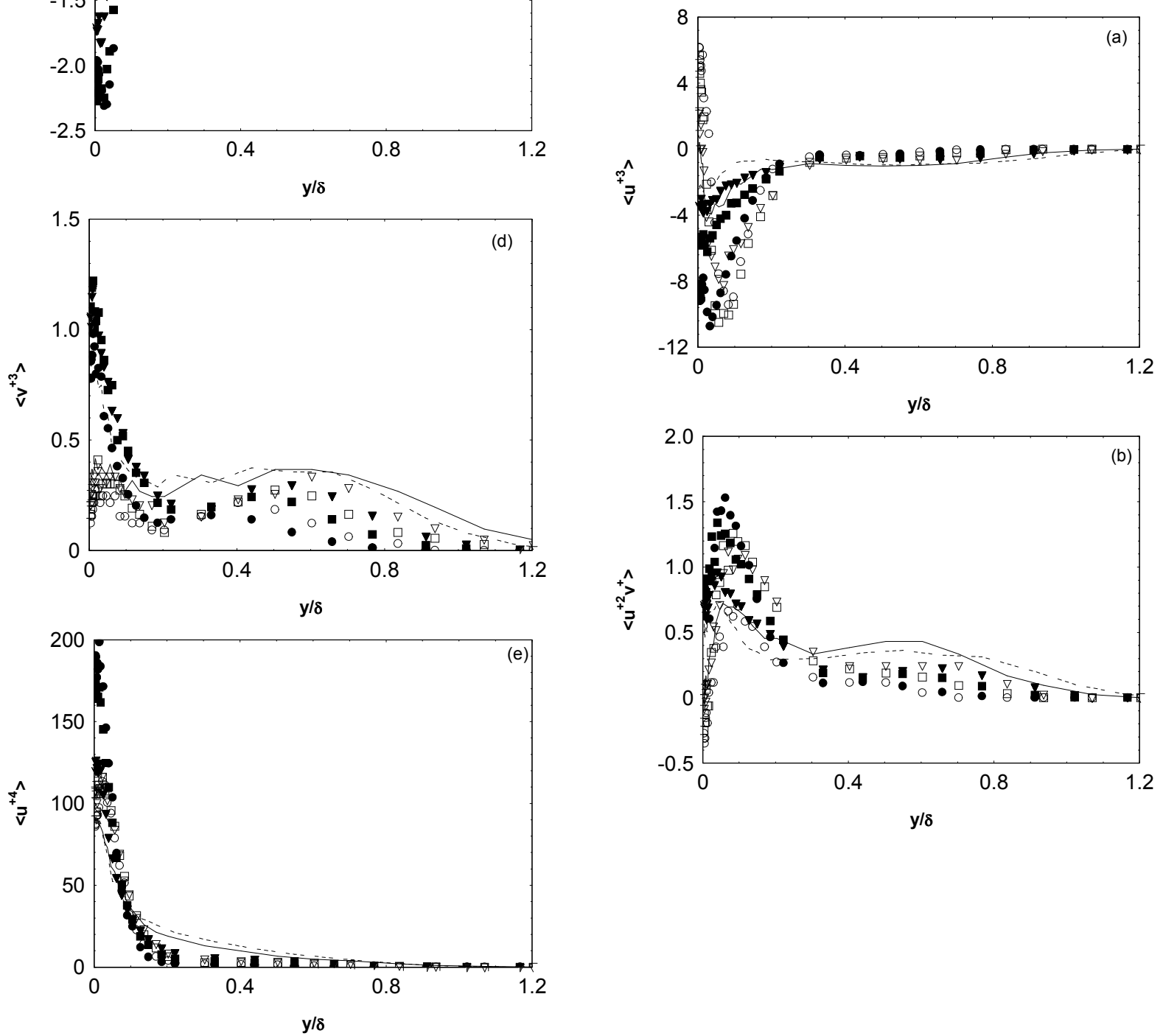

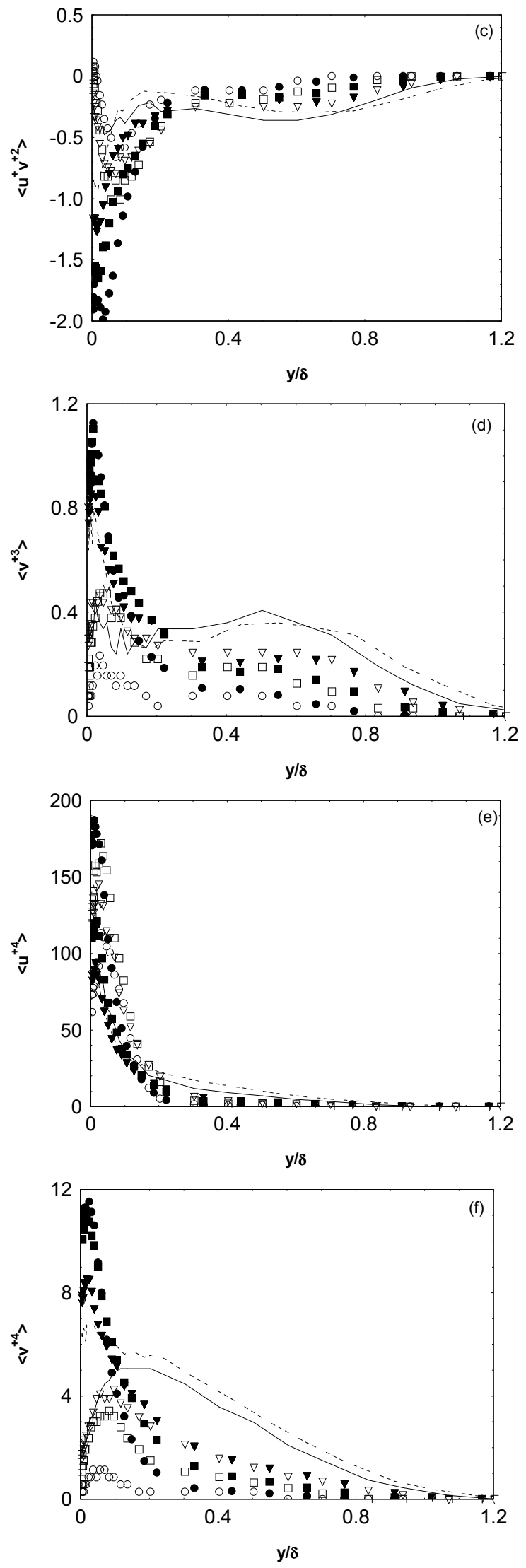

Figure 4. Distribution of normalised third- and fourth-order statistics at $\mathrm{x} / \delta=10$ for several suction rates. (a) $<\mathrm{u}^{+3}>$; (b) $<\mathrm{u}^{+2} \mathrm{v}^{+}>$; (c) $<\mathrm{u}^{+} \mathrm{v}^{+2}>$; (d) $<\mathrm{v}^{+3}>$; (e) $<\mathrm{u}^{+4}>$; (f) $<\mathrm{v}^{+4}>$. Symbols are as in Figure 2 .
The effect of change in the Reynolds number (from 660 to 1400) on the suction effect on the third and fourth-order turbulent statistics are evidences in all the distribution. While the behaviour of the distributions at $R_{\theta o}=1400$ is qualitatively similar to that of the $R_{\theta o}=660$ when suction is applied, the change in the Reynolds number modulates the magnitude of the effect of suction on the quantities. This would suggest an intensification of the near-wall coherent structures when the Reynolds number is increased. Also, taking into consideration that the zero suction boundary layer characteristics does not change appreciably with Reynolds number in the inner region. The changes observed in the near-wall region with suction when the Reynolds number increases would suggest the influence of Reynolds number on the suction effect on the boundary layer. The present results corroborate those of Oyewola et al. (2003), which observed similar Reynolds number influence on the suction effect on the mean flow quantities as well as on the Reynolds stresses. Based on the present measurements and those of Oyewola et al. (2003), it is proposed that the influence of Reynolds number on the suction effect in a turbulent boundary layer is universal especially for the largescale quantities. Interestingly, when the Reynolds number increases, the outer region of the boundary layer is not sensitive to any change on the suction effect. This may suggest that the effect of Reynolds number on the influence of suction is likely to be confined to the inner region of the boundary layer. This is not surprising since turbulent activities are more pronounced in this region of the boundary layer, and suction acts to interfere with these activities. In that respect, the effect of suction on the boundary layer is likely to be more prominent in the inner region.

While the individual rate of recovery of the thirdand fourth-order statistics is being influenced by $\sigma$, this is not change by increase in the Reynolds number. Reynolds number controls the streamwise location of the recovery. For example, with increase in the Reynolds number (from 660 to 1400), the recovery is quicker especially at the near-wall region. Also, with increase in the Reynolds number, the overshoot increases. Interestingly, the recovery of the outer region is not been influenced by increase in the Reynolds number.

The results of third- and fourth-order turbulent statistics revealed a significant change in the nearwall turbulence activities. Further quantification of these changes are provided by the measurements of the root mean square of the fluctuating vorticity component in the spanwise direction. Figure 5 shows the distribution of the measured r.m.s. fluctuating spanwise vorticity normalised with variables $U_{\infty}$ and $\delta$ for $R_{\theta o}=660$ and 1400 . It should be noted that measurement was not made for $\sigma=5.5$ when $\mathrm{R}_{\theta \mathrm{o}}=$ 1400. Also shown in the figure is the measured data of Rajagopalan and Antonia (1993). The present no 
suction data show a reasonable agreement with that of Rajagopalan and Antonia (1993) in the region 0.1 $<\mathrm{y} / \delta<0.4$, especially when $\mathrm{R}_{\theta \mathrm{o}}=1400$. Similarly, the non-suction data at $\mathrm{R}_{\theta 0}=1400$ collapsed reasonably well with the DNS data of Spalart (1988) (not shown) for $\mathrm{y} / \delta>0.15$. The main result emerging from the distribution is that the normalised r.m.s. fluctuating spanwise vorticity is reduced over a significant fraction of the boundary layer when suction is applied, although the reduction is largest near the wall. The departure from no suction case increases as the suction increases, but reduces when the Reynolds number is increased. The reduction can be linked to a stabilisation of the near-wall vortical structures. Djenidi et al.'s flow visualisations (2002) showed that suction have a stabilising effect in the spanwise direction. The effect of this stabilisation is likely to weaken the vorticity, and thus diminish the strength of the vortices in the near-wall region of the boundary layer. This would modify the turbulence level downstream of the strip. This argument is consistent with the reduction in the Reynolds stresses in the near-wall region observed in Oyewola et al.'s study (2003). Also, since high internal shear layer which contributes significantly to $\omega_{z}^{\prime}\left(\omega_{z}=\partial v / \partial x-\right.$ $\partial \mathrm{u} / \partial \mathrm{y}$ ) existing in the region near the wall plays a significant role in the dynamics of the boundary layer (Johansson et al., 1987), the reduction observed in the normalised rms fluctuating spanwise vorticity may suggest that the near wall dynamics of the layer has been altered by suction. The outer effect is that the near-wall structures downstream of the suction strip would be of reduce intensity. The present data (Figure 5) indicate that the magnitude of the response of the r.m.s fluctuating spanwise vorticity to suction reduces as the Reynolds number increases. This would suggest that the near-wall vortices becomes more intensified as the Reynolds number increases, which in turn would reduce the effect of suction.

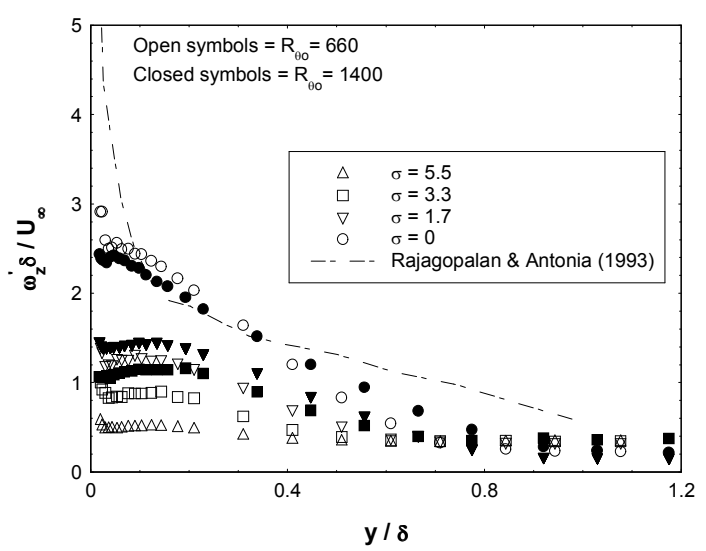

Figure 5. Distribution of normalised r.m.s fluctuating spanwise vorticity at $\mathrm{x} / \delta=3$ for several suction rates. Open symbols $=R_{\theta o}=660$ and closed symbols $=\mathrm{R}_{\theta \mathrm{o}}=1400$.

\section{CONCLUSIONS}

In this paper, an experimental study was carried out in order to examine the effect of Reynolds number on the influence of suction on the turbulent boundary layer structures. Measurements of third and fourth-order turbulent statistics were made for $\mathrm{R}_{\theta_{\mathrm{o}}}=$ 660 and 1400 for several suction rates and streamwise locations. The results indicate that, relative to no suction case, the distributions of the third and fourth-order turbulent statistics showed a considerable reduction both in the inner and outer regions. The result indicates that suction alters the turbulent transport of the Reynolds stresses due to the suppression of the near-wall quasi-coherent structures. The effect of which would lead to the change in the organise motions of the boundary layer. This is evidenced in the changes observed in the rms fluctuating spanwise vorticity when suction is applied. The result suggests that suction alter the dynamics of the boundary layer structures. The effect of which is increased as the suction rate is increased, but is reduced as the Reynolds number is increased.

The effect of Reynolds number on the suction effect on third and fourth-order quantities is apparent throughout the boundary layer. Reynolds number quantitatively controls the effect of suction on the higher-order turbulent statistics without changing it qualitatively. The present measurements in conjunction with Oyewola et al. (2003) proposed that Reynolds number influence of the suction effect in a turbulent boundary layer is universal especially for the large-scale quantities.

\section{ACKNOWLEDGEMENTS}

The author gratefully acknowledged the support of Prof Antonia and Dr. Djenidi. Also, the assistant of Miss Yemisi Ogunlola is gratefully acknowledged.

\section{REFERENCES}

Antonia, R. A., Fulachier, L., Krishnamoorthy, L. V., Benabid, T., Anselmet, F., 1988, Influence of wall suction on the organized motion in a turbulent boundary layer, Journal of Fluid Mechanics, Vol. 190, pp. 217-240.

Antonia, R. A., Zhu, Y., Sokolov, M., 1995, Effect of concentrated wall suction on a turbulent boundary layer, Physics of Fluids, Vol.7, pp. 24652475.

Bradshaw, P., 1967, Inactive motion and pressure fluctuations in turbulent boundary layers, Journal of Fluid Mechanics, Vol.30, pp. 241-258.

Cantwell, B. J., 1981, Organized motion in turbulent flow, Annual Review of Fluid Mechanics, Vol. 13, pp. 457. 
Chacin, J. M., Cantwell, B. J., 2000, Dyamics of a low Reynolds number turbulent boundary layer, Vol. 404, pp. 87-115.

Djenidi, L., Vincent, A., Gall, P-E., Antonia, R. A., 2002, Effect of wall suction on the structure of a turbulent boundary layer, Proceedings of the $11^{\text {th }}$ Int. Symp. on the Application of Laser Techniques to Fluid Mechanics, Lisbon, Portugal, 8-11 July, 23-1 (available on CD ROM Ponteiromágico, electronic edition, LDA, Lisbon).

Jeong, J. Hussain, F., Schoppa, W., Kim, J., 1997, Coherent structures near the wall in turbulent channel flow, Vol. 332, pp. 185-214.

Johansson, A. V., Alfredsson, P. H., 1982, On the structure of turbulent channel flow, Journal of Fluid Mechanics, Vol. 122, pp. 295-314.

Johansson, A. V., Alfredsson, P. H., Eckelmann, H., 1987, On the evolution shear-layer structures in near-wall turbulence, In Advances in Turbulence, Springer-Verlag, Berlin, pp. 383-390.

Kline, S. J., Reynolds, W. C., Schraub, F. A., Runstadler, P. W., 1967, The structure of turbulent boundary layers, Journal of Fluid Mechanics, Vol. 30, pp. 741-773.

Krogstad, P-A., Kourakine, A. 2000, Some effects of localised injection on the turbulence structure in a boundary layer, Physics of Fluids, Vol.12, pp. 2990-2999.

Oyewola, M. O, 2004, Influence of Reynolds number on the suction effect on a turbulent boundary layer structures, Proceedings of the $10^{\text {th }}$ Brazilian Congress of Thermal Sciences and Engineering, Paper No 0614.

Oyewola, O., Djenidi, L., Antonia, R. A., 2003, Combined influence of the Reynolds number and localised wall suction on a turbulent boundary layer, Experiments. in Fluids, Vol.35, pp. 199-206.

Oyewola, O., Djenidi, L., Antonia, R. A., 2001, Effect of wall suction on a turbulent boundary layer: Reynolds number dependence, Proceedings of 14th Australasian Fluid Mechanics Conference, Adelaide, edited by B.B. Dally, pp. 239-243.

Park, J., Choi, H., 1999, Effects of uniform blowing or suction from a spanwise slot on a turbulent boundary layer flow, Physics of Fluids, Vol. 11, pp. 3095-3105.

Rajagopalan, S., Antonia, R. A., 1993, RMS spanwise vorticity measurements in a turbulent boundary layer, Experiments in Fluids, Vol. 14, pp. 142-144.

Robinson, S. K., 1991, Coherent motions in the turbulent boundary layer, Annual Review of Fluid Mechanics, Vol.23, pp. 601-639.

Sano, M., Hirayama, N., 1985, Turbulent boundary layer with injection and suction through a slit; first report: mean and turbulence characteristics, Bulletin of Japan Society of Mechanical Engineers, Vol.28, pp. 807-814.
Spalart, P. R., 1988, Direct simulation of a turbulent boundary layer up to $\mathrm{R}_{\theta}=1410$, Journal of Fluid Mechanics, Vol.187, pp. 61-98. 